\title{
Incisional Hernia Repair with Abdominoplasty
}

\author{
Hesham H Wagdi, Mostafa A Mohamed, Mohamed A Aboul Naga, Ahmed R Nassem \\ Department of General Surgery, Faculty of Medicine, Ain Shams University \\ Corresponding author: Ahmed R Nassem; Mobile: 01002760066; Email: maxpayne9933@ gmail.com
}

\begin{abstract}
Background: Abdominoplasty is considered by many general surgeons as only an aesthetic technique. It has shown to provide great benefits for patients: (1) removal of excessive skin, which promotes better local hygiene and reduces incidence of skin infections; (2) strengthening of muscular bending (better muscular tone, corporal position, and then de-ambulation); (3) stabilization of the lumbar spine level (by changing the angle of lumbar lordosis and sacral inclination, improving the chronic low back pain), scar removal and, finally, a better perception of their bodies (higher selfesteem, satisfaction and quality of life), less anxiety and better personal relationships. All these changes are always desirable for all patients. Aim of the Work: The main objective of our study is to assess the outcome of the combined procedure of abdominoplasty and incisional hernioplasty, compared to incisional hernioplasty alone. Patients and Methods: This randomized comparative study was carried out on fourty patients having incisional hernias in General Surgery and Plastic Surgery Departments in Ain Shams University and AL Salam Specialized Hospital. Hernias are included in this study and divided into two groups, each group formed of 20 patients. First group (group A) with patients underwent hernioplasty alone and the other group (group B) with patients underwent combined hernioplasty with abdominoplasty. Patients are explained that they have the right to refuse joining to the research or withdraw at any time without affecting their chances to receive the optimal treatment at any time. Patients are explained the significant risks and the problems specific to them as well as the likely outcome if complications occurred and the relevant treatment options as well as the risks of not having the procedure. Results: According to size of hernia hernioplastywas 4.20 and abdominoplasty was 5.45. According to type of suture PDS loop hernioplasty was $15.0 \%$, abdominoplasty was $75.0 \%$ and Prolene hernioplasty was $85 \%$ abdominoplasty was $25 \%$. Conclusion: Abdominoplasty can be performed in combination with hernia repair in patients with incisional hernias, especially when associated with large sized defects or divercation of recti. Simultaneous techniques can be safely performed with the same morbidity and recurrences, but with major quality of life improvement and superiority over hernioplasty alone.
\end{abstract}

Key words: Hernia, Incisional Hernioplasty, Abdominoplasty

\section{INTRODUCTION}

Incisional hernias are often associated with an excess of skin and fat, laxity or muscle relaxation and abdominal shape deformity with hernia bulge and scars. This set of changes has an impact on physical and mental health of patients such as back pain, digestive disorders, eating disorders, urinary incontinence, increased tendency to depression and stress ${ }^{(\mathbf{1})}$.

The development of incisional hernias represents one of the commonest late complications following open abdominal surgery. Literature searches reveal post-laparotomy incisional hernia rates of $4-18 \%$, in series with follow-up of 1-5 years, with over $75 \%$ of these occurring within two years of the initial surgery. Following laparoscopic resection, hernias may develop in the port-sites or the specimen removal site ${ }^{(2)}$.

Risk factors of incisional hernia includes increasing age, male gender, undergoing emergency surgery, history of smoking, anaemia, prostate hypertrophy, cough, chronic obstructive pulmonary disease and significant post-operative wound problems or infection. Furthermore, patients with a body mass index greater than $31 \mathrm{~kg} / \mathrm{m} 2$ are prone to develop incisional hernia ${ }^{(3)}$.

Incisional hernias, although often asymptomatic and rarely leading to obstruction or strangulation, can remain troublesome and unsightly to patients. This is representing significant burden upon healthcare resources, such as radiological imaging, outpatient review and surgical correction ${ }^{(2)}$.

The most frequent complications of incisional hernia repair are seroma, hematoma, abscess formation and abdominal wall pseudocyst. Abdominal CT scanning is useful to differentiate the pseudocyst from recurrent incarcerated incisional hernia ${ }^{(4)}$.

The ideal reconstruction would be one that corrects and prevents visceral eventration, provides dynamic muscle support and allows for tensionfree repair during a one stage procedure ${ }^{(5)}$.

Transverse rather than vertical incisions and the use of monofilament, slowly-absorbable or non-absorbable, continuous sutures during abdominal fascial closure have been associated with decreased development of incisional hernias. 
However, the results of randomized trials utilizing various mesh products in obese patients, who are at high-risk of incisional hernias, have been inconclusive. One study suggesting that polypropylene meshes may assist in the prevention of incisional hernia development. Another study reporting no significant beneficial effect following use of a polyglactin mesh ${ }^{(2)}$.

Technique developed for the surgical approach to abdominoplasty include the use of the transverse lower abdominal incision and the resection of excess skin. Robertson et al. described the incorporation of this technique into the surgical management of ventral incisional hernia. Since 80s, this method has been used in selected patients with ventral incisional hernias. These patients include those with multiple recurrent hernias, obese patients with unrepaired incisional or spontaneous hernias and those with multiple concurrent hernias. The benefits of this approach are full exposure of the abdominal wall defect, a surgical approach through known tissue planes, and a fascial repair remote from the skin incision. By incorporating these aspects into hernia repair, the safety of the procedure is maintained, the recurrence rates are low, and the aesthetic outcomes are improved ${ }^{(5)}$.

Abdominoplasty is one of the most common aesthetic procedures performed. One of The primary indications for the procedure is skin and fascial laxity, which is often found in multiparous women. A frequentlyencountered problem associated with the occurrence of fascial laxity or diastasis is abdominal wall. Hernia traditional surgical techniques for performing abdominoplasty include skin incisions circumferentially around the umbilicus, resulting in complete detachment of the umbilicus from the anterior abdominal flap. As a result, the umbilicus maintains its only blood supply from the underlying fascial attachments via the umbilical stalk ${ }^{(6)}$.

\section{AIM OF THE WORK}

The main objective of our study is to assess the outcome of the combined procedure of abdominoplasty and incisional hernioplasty, compared to incisional hernioplasty alone.

\section{PATIENTS AND METHODS}

\section{Patients:}

This randomized comparative study was done in the period between August 2014 and December 2016. This study was carried out in
General Surgery and Plastic Surgery Departments in Ain Shams University and AL Salam Specialized Hospital. Fourty patients having incisional hernias are included in this study and divided into two groups, each group formed of 20 patients. First group (group A) with patients underwent hernioplasty alone and the other group (group B) with patients underwent combined hernioplasty with abdominoplasty.

Patients are explained that they have the right to refuse joining to the research or withdraw at any time without affecting their chances to receive the optimal treatment at any time. Patients are explained the significant risks and the problems specific to them as well as the likely outcome if complications occurred and the relevant treatment options as well as the risks of not having the procedure.

All patients signed an informed consent form and all procedures were performed in accordance with good clinical practice guidelines. The medical records of these patients were reviewed retrospectively and the following data were collected for each patient. The study was approved by the Ethics Board of Ain Shams University.

Inclusion criteria: Inclusion criteria include all the following: Patients with age more than 20 years and less than 60 years old. Female patients. Patients having incisional hernias. Patients with BMI: more than $25 \mathrm{~kg} / \mathrm{m}^{2}$. Patients with an American Society of Anesthesiology (ASA) classification of 3 or less with no major comorbidity as cardiopulmonary, hepatic, or renal impairment.

Exclusion criteria: Exclusion criteria were all the following: Patients with age less than 20 years and more than 60 years old. Male patients. All other types of hernias except incisional. Patients with BMI: less than $25 \mathrm{~kg} / \mathrm{m}^{2}$. patients with ASA classification higher than 3 .

History and Physical Examination: In this study, incisional hernia was defined as any abdominal wall gap with a bulge in the area of a postoperative scar perceptible or palpable by clinical examination. All the patients were evaluated by having a detailed clinical history, a directed comprehensive examination. Examination of the skin of the abdominal wall for striae with 
thinning or absent dermis, was done. Midline diastasis of recti abdominis was recorded.

\begin{tabular}{ccc} 
Pre-operative evaluation: Routin & \multicolumn{2}{c}{ laboratory investigations included $\mathrm{CBC}$}
\end{tabular}
Coagulation profile, liver functions, renal functions, serum albumin and fasting and postprandial blood glucose levels. Risk factors such as smoking, diabetes, obesity, were addressed prior to surgery, in order to optimise outcomes after hernia repair. Cessation of smoking for at least 3 months prior to surgery. Optimising glycaemic control for diabetic patients is important. It is beneficial to keep the blood glucose normal during the first 24 hours after surgery. Weight loss before surgery was strongly recommended in obese patients with a BMI greater than 35. Hernia repair preceded by physician monitored medical weight loss, concomitant hernia repair with weight loss surgery, are all viable options to approach this problem. Mucolytic agents and respiratory physiotherapy (including intercostal muscle and diaphragm exercises) were applied for patients with lung disease. Associated diseases (cardiac conditions, hypertension, and diabetes) were treated and stabilized when present. Disinfection of skin folds, and treatment of associated. Fungal infections or other skin lesions when required before surgery. Antibiotic prophylaxis in the form of a single dose of 3rd generation cephalosporin was administered within 60 minutes before skin incision.

\section{Methods}

\section{Surgical procedure:}

\section{Hernioplasty}

Anaesthetic technique: General anaesthesia is most often used, but in certain situations, regional or local anaesthesia can be applied depending on the site and size of the hernia.

Positioning and skin incision: The incision is planned and marked either in transverse or longitudinal or oblique directions according to the defect and site of hernia. All efforts are done to include the old scar mostly by elliptical incision. The patient is usually in supine position. The skin is prepared and sterilized according to the site of hernia.

Procedure: The skin incised and dissecting in a way to include the previous scar. Dissection of the subcutaneous underluing using the coagulation property of the diathermy in order to control the bleeding. Identification and dissection of the hernia sac from the overlying subcutaneous tissue by creation of skin flaps on both sides of the incision. The sac was dissected all around till reaching and identifying the edges of neck of the sac. The sac is incised usually at its neck and not at the fundus for fear of presence of adhesions between walls of the sac and its contents. After reduction of the contents of the sac whether bowel loops or omentum, the sac is freed from the sheath at its neck. Then, the defect is repaired by a strong non-absorbable prolene 1 or 0 suture by a starting stitch beyond the defect and continued all the length of the defect with $1 \mathrm{~cm}$ apart from the edges and $1 \mathrm{~cm}$ in between the stitches. After completion of the repair of the defect, good hemostasis is assured. Polypropylene mesh with size $15 \times 15 \mathrm{~cm}$ is placed by onlay technique over repaired anterior abdominal wall muscles and fixed by interrupted or continuous stitches prolene $3 / 0$ or $4 / 0$ stitches. A closed system drain under negative suction is placed to assure no post-operative collection over the mesh for fear of infection. The subcutaneous tissue is approximated by interrupted absorbable stitches. The skin is closed by subcuticular stitch for better cosmosis of the wound.

\section{Combined hernioplasty with abdominoplasty}

Anaesthetic technique: General anaesthesia is most often used with endotracheal intubation.

Positioning and skin incision: Preoperative markings were crucial to successful surgery and to get desired symmetrical results. The patient was marked in the recumbent and standing positions, noting the midline and planned incisions. A transverse line was made just above the pubic hair extending laterally 7 to $18 \mathrm{~cm}$ in each direction towards the anterior superior iliac spine. All patients had sequential compression devices placed prior to induction. The patient is usually in supine position, with the arms extended $90^{\circ}$ when possible.and secured on arm boards. A pillow was placed under the knees. Preparation and sterilization of the operative field was done with a wide skin prep and draping. Each patient was prepared from xiphoid to the midthighs, and as far laterally as possible.

\section{Procedure:}

A transverse skin incision, following the previously determined markings, is done in the lowest skin crease above the pubic hairline and dissection was continued through the Scarpa's fascia to the deep fascia of the abdominal wall. A circular incision surrounding the umbilicus and 
extending down to the rectus sheath to creat an umbilical stalk which is completely freed from the surrounding adipo-cutaneous tissue in a manner to preserve its blood supply.

After exposure of the hernia sac, dissection was carried all around targeting to separate the sac of the hernia from the overlying adipo-cutaneous tissue till reaching the edges of the defect of the sac. The sac is dissected and detached completely from its adjacent structures till completely separated from edges of the defect and then contents of the sac are reduced.

The flap was elevated at the level of the deep fascia and dissection was carried out both sharply and with electrocautery. Flap dissection is continued up to the xyphoid and medial costal margins avoiding lateral undermining to preserve the intercostal perforators to the flap. Careful hemostasis was performed with diathermy

In most cases, we used a triangular dissection that was wider inferiorly and narrowest at the level of the xyphoid.

When dissection was complete and after complete removal of the sac, the defect is repaired by either non-absorabable 0 or 1 prolene or longacting absorbable sutures like Nylon or PDS loop. We usually use running sutures to close the defect.

Then, the linea alba was recreated by midline plicating sutures with long-acting absorbable sutures like Nylon or PDS loop in a running continuous manner with a locking stitch every 3-4 sutures reinforced by a stay suture using vicryl 0 or 1 stitch. We start as much far as the epigastrium and following in a manner of area increasing in width as descending to the pubis and sparing the stalk of the umbilicus, placating the weak anterior abdominal wall. Plication is done above and below the umbilicus symmetrically on both sides of the midline.

After achieving good hemostasis, we placed prolene mesh by on lay technique over the plicated anterior abdominal wall and the mesh was fixed to the abdominal wall with $3 / 0$ prolene sutures till it is completely secured.

Then, the patient was brought to a flexed position of approximately $45^{\circ}$ to $60^{\circ}$ at the hips, with the knees bent slightly and the bed was placed in the Trendelenburg position so that the torso was parallel to the floor.

The flap was pulled down and the amount of excess tissue was determined, marked and the redundant skin and fat were excised.

Another way to create the umbilicus when it's involved in the hernia defect is to remove the umbilicus and create a new one. A 2-cm circle of the overlying flap was defatted, and a circular or vertically oriented oval of skin was excised. From the underside of the flap, 3-0 Vicryl was placed in a 3point suture formation from the abdominal skin dermis to the umbilical stalk dermis to the muscle fascia at 12, 3, 6 and 9 o'clock around the stalk. Tying of the sutures created a neoumbilical depression and splinted the umbilical incision from contracture. The umbilical skin edges were approximated with a few interrupted 5-0 Prolene. One or two negative pressure closed drainage is placed.

We placed midline sutures to secure the flap in place in the midline of the suprapubic. Lateral sutures were placed more sparsely, and care was taken to place them symmetrically, from side to side.

The wound was closed (tension free) in two layers, vicryl 3-0 or 2-0 stitches were applied to fix the scarpa's fascia of the superior abdominal flap to the inferior scarpa fascia border. The skin was closed with 4-0 Vicryl deep dermal sutures and a running 3-0 prolene subcuticular suture.

\section{Postoperative care:}

Patients were observed overnight in hospital. Pain was well controlled. Patients were ambulated as early as possible after surgery. A compressive binder was used on all patients for comfort and abdominal support.

For the group B patients with combined hernioplasty and abdominoplasty: patients were encouraged to walk as upright as tolerable. While ambulating or recumbent, patients were not required to maintain a hipflexed position.

\section{Postoperative Follow-up:}

Patients were discharged when their autonomy was recovered, pain was under control, and the surgical team was satisfied with the absence of obvious immediate complications. Patients were clinically reevaluated 7 days and $1,6,12$, and 24 months after 
surgery. Drains over the mesh and in the subcutaneous plane were removed after two weeks. Suction drains were removed when the output is less than $50 \mathrm{ml}$ of serous fluid per day for group A patients who wnderwent hernioplasty alone and for the group B patients, with combined hernioplasty and abdominoplasty, usually after two weeks again when the discharged fluid is serous and less than $50 \mathrm{ml}$ per day.

Patients were encouraged to increase activities as tolerated but were advised to avoid strenuous exercise, abdominal exercise, and lifting of greater than 5 kilograms for the first 6 weeks postoperatively.

After being discharged, patients were followed up at the surgical outpatient clinic closely for their wounds and assessment of their general and aesthetic condition. Then, they were followed upwith a thorough physical examination, every 3 months for 2 years.

\section{Data Management and Analysis:}

The collected data were revised, coded, tabulated and introduced to a personal computer (PC) using statistical package for social science (SPSS 15.01 for windows). Data were presented and suitable analysis was done according to the type of data obtained for each parameter.

i. Descriptive statistics: 1. Mean. 2 . Minimum and maximum values (range) for numerical data. 3. Frequency and percentage of non-numerical data.

ii. Analytical statistics: 1. Independent Samples T Test: was used to assess the statistical significance of the difference between two study group means. 2. Fissure exact test: was used to assess the statistical significance of the difference between two study group medians (quantitative non parametric data). 3. ChiSquare test: was used to examine the relationship between two qualitative variables: Pvalue: level of significance: $\mathrm{P}>0.05$ : Non significant (NS). $\mathrm{P}<$ 0.05: Significant $(\mathrm{S})$. $\mathrm{P}<0.01$ : Highly significant (HS).

\section{RESULTS}

Table (1): The clinicopathological characteristics of patients with incisional hernias in the presented study.

\begin{tabular}{|c|c|c|c|c|c|}
\hline & Hernioplasty & Abdominoplasty & \multirow{2}{*}{$\begin{array}{c}\text { Test } \\
\text { value }\end{array}$} & \multirow{2}{*}{$\begin{array}{c}\text { P- } \\
\text { value }\end{array}$} \\
\hline & & No. $=20$ & No. $=20$ & & \\
\hline Age & $\begin{array}{l}\text { Mean } \pm \text { SD } \\
\text { Range }\end{array}$ & $\begin{array}{c}39.45 \pm 7.09 \\
30-54\end{array}$ & $\begin{array}{c}45.15 \pm 7.41 \\
35-57\end{array}$ & $-2.485 \bullet$ & 0.017 \\
\hline $\begin{array}{l}\text { Body mass } \\
\text { index (BMI) } \mathrm{kg} / \mathrm{m}^{2}\end{array}$ & $\begin{array}{l}\text { Mean } \pm \text { SD } \\
\text { Range }\end{array}$ & $\begin{array}{c}32.25 \pm 3.65 \\
26-38\end{array}$ & $\begin{array}{c}31.70 \pm 5.68 \\
27-44\end{array}$ & $0.364^{\bullet}$ & 0.718 \\
\hline $\begin{array}{l}\text { Type of primary } \\
\text { operation }\end{array}$ & $\begin{array}{l}\text { Appendicetomy } \\
\text { Cesarean Section } \\
\text { cholecystectomy } \\
\text { Exploration } \\
\text { laparoscopic } \\
\text { sleeve } \\
\text { gastrectomy } \\
\text { open } \\
\text { cholcystectomy }\end{array}$ & $\begin{array}{l}6(30.0 \%) \\
4(20.0 \%) \\
2(10.0 \%) \\
5(25.0 \%) \\
3(15.0 \%) \\
0(0.0 \%)\end{array}$ & $\begin{array}{c}0(0.0 \%) \\
6(30.0 \%) \\
0(0.0 \%) \\
5(25.0 \%) \\
4(20.0 \%) \\
5(25.0 \%)\end{array}$ & $13.543 *$ & 0.019 \\
\hline $\begin{array}{l}\text { Size of the hernia } \\
\text { defect }(\mathrm{cm})\end{array}$ & $\begin{array}{l}\text { Mean } \pm \text { SD } \\
\text { Range }\end{array}$ & $\begin{array}{c}4.20 \pm 2.17 \\
2-8\end{array}$ & $\begin{array}{c}5.45 \pm 1.61 \\
4-9\end{array}$ & $-2.073 \bullet$ & 0.045 \\
\hline Reducibilty & $\begin{array}{l}\text { No } \\
\text { Yes }\end{array}$ & $\begin{array}{c}4(20.0 \%) \\
16(80.0 \%) \\
\end{array}$ & $\begin{array}{c}4(20.0 \%) \\
16(80.0 \%) \\
\end{array}$ & $0.000 *$ & 1.000 \\
\hline Site of hernia & \begin{tabular}{|l} 
Epigastric \\
Flank \\
Iliac \\
Infraumbilical \\
lumbar \\
Subcostal \\
Suprapubic \\
Umbilical \\
\end{tabular} & $\begin{array}{c}5(25.0 \%) \\
0(0.0 \%) \\
6(30.0 \%) \\
0(0.0 \%) \\
3(15.0 \%) \\
0(0.0 \%) \\
2(10.0 \%) \\
4(20.0 \%) \\
\end{array}$ & $\begin{array}{c}2(10.0 \%) \\
3(15.0 \%) \\
0(0.0 \%) \\
5(25.0 \%) \\
0(0.0 \%) \\
2(10.0 \%) \\
6(30.0 \%) \\
2(10.0 \%) \\
\end{array}$ & $22.952 *$ & 0.002 \\
\hline Hypertention & $\begin{array}{l}\text { No } \\
\text { Yes } \\
\end{array}$ & $\begin{array}{l}18(90.0 \%) \\
2(10.0 \%) \\
\end{array}$ & $\begin{array}{c}16(80.0 \%) \\
4(20.0 \%) \\
\end{array}$ & 0.784* & 0.376 \\
\hline Diabetes & $\begin{array}{l}\text { No } \\
\text { Yes }\end{array}$ & $\begin{array}{l}18(90.0 \%) \\
2(10.0 \%) \\
\end{array}$ & $\begin{array}{c}16(80.0 \%) \\
4(20.0 \%) \\
\end{array}$ & $6.144^{*}$ & 0.013 \\
\hline Other co-morbidities & $\begin{array}{l}\text { Left partial } \\
\text { nephrectomy } \\
\text { Splenectomy }\end{array}$ & $\begin{array}{l}2(40.0 \%) \\
3(60.0 \%)\end{array}$ & $\begin{array}{l}0(0.0 \%) \\
0(0.0 \%)\end{array}$ & NA & NA \\
\hline
\end{tabular}

*: Chi-square test

As regards age as shown in the table above, group $\mathrm{A}$ of patients with incisional hernias who underwent hernioplasty alone: the mean age was 39.45 years (range from 30 - 54 years). Group B patients who underwent combined procedure of abdominoplasty and hernioplasty: the mean age was 45.15 years (range from 35-57 years). This shows statistical significant difference between the two groups as reagarding age (P-value 0.017), indicating older patients are in need for the combined procedure abdominoplasty and hernioplasty than younger patients. This may be due to increasing weakness of abdominal wall muscles related to age.

Patients in group A had body mass index (BMI) ranged from $26-38 \mathrm{~kg} / \mathrm{m} 2$ in comparison to 27- $44 \mathrm{~kg} / \mathrm{m} 2$ in patients of group B. This implies that BMI has no significant effect about the choice of the operation between hernioplasty or the combined procedure abdominoplasty and hernioplasty ( $\mathrm{p}$ value $0.718)$.

History of types of primary surgery for these incisional hernias was recorded and specified. In group A patients operations were specified into: Appendicectomy (6 patients, $30 \%$ ), cesarean section 
(4 patients, $20 \%$ ), cholecystectomy (2 patients, 10 $\%$ ), exploration (5 patients, $25 \%$ ), laparoscopic sleeve gastrectomy (3 patients, $15 \%$ ) and open cholecystectomy (0 patients $0 \%$ ). Compared to patients in group B: Appendicectomy ( 0 patients, 0 $\%)$, cesarean section (6 patients, $30 \%)$, cholecystectomy ( 0 patients, $0 \%)$, exploration (5 patients, $25 \%$ ), laparoscopic sleeve gastrectomy (4 patients, $20 \%$ ) and open cholecystectomy (5 patients $25 \%$ ). This lead to a significant difference with $\mathrm{p}$ value 0.019 implying that patients having incisional hernias due to major surgeries are in need for combined hernioplasty and abdominoplasty.

The size of the hernia defect ranged from 2 $-8 \mathrm{~cm}$ with a mean of about $1.2 \mathrm{~cm}$ in group A patients in comparison to a range of $4-9 \mathrm{~cm}$ with a mean of $5.45 \mathrm{~cm}$ in group B. The p value was 0.045 which showed a significant difference. The need for combined hernioplasty and abdominoplasty is more with large sized hernial defect.

In group A, there was 4 patients (20\%) with irreducible incisional hernias who underwent hernioplasty alone, the same number of patients had underwent combined hernioplasty and abdominoplasty procedure with no significant difference.

As regarding the incidence of associated morbidities: Hypertention was revealed in 2 patients $(10 \%)$ in group A while it was present in about 4 patients $(20 \%)$ in group B with no statistical difference. Again, no statistical difference between the studied groups as regards the incidence of diabetes mellitus, whereas it was present in about 2 patients $(10 \%)$ in group A comapared to 4 (20\%) in group B. Two patients in group A gave history of left partial nephrectomy for benign lesions while three patients in group A gave history of splenectomy. This surgical history also showed no significant statistical difference between both groups.

Sites of incisional hernias in patients of group A, were recorded as the following: epigastric (5 pateints, $25 \%$ ), iliac (6 patients, 30\%), Infraumbilical (0 patients), lumbar (3 patients, 15\%), subcostal (0 patients), suprapubic (2 patients, 10\%) and umbilical (4 patients, $20 \%$ ). While in group B, hernias were present in the following sites: epigastric (2 pateints, $10 \%$ ), flank (3 patients, $15 \%)$, iliac (0 patients,
$0 \%)$, Infraumbilical (5 patients, $25 \%)$ ), lumbar (0 patients, 0\%), subcostal (2 patients, 10\%), suprapubic (6 patients, 30\%) and umbilical (2 patients, $10 \%)$. These data were associated with a highly significant statistical difference between the studied groups " $p$ value 0.002 ".

As regards data related to surgery in the present study, the type of repair suture during surgery, we applied the contunious ruuning sutures while repairing the hernia defect in all 20 patients in group B $(100 \%)$ underwent combined abdominoplasty and hernioplasty in comparison to 14 patients $(70 \%)$ in group $\mathrm{A}$ underwent hernioplasty alone while in the other 6 patients (30 $\%)$, the interrupted pattern was used. This showed a significant difference ( $p$ value 0.008 ). This implies that the continuous pattern of sutures is more needed during repair of hernias to assure similarity and distribution of tension all over the repair.

Table (2): Data related to the surgery in the present study.

\begin{tabular}{|c|c|c|c|c|c|}
\hline & Hernioplasty & Abdominoplasty & \multirow{2}{*}{$\begin{array}{c}\text { Test } \\
\text { value }\end{array}$} & \multirow{2}{*}{$\begin{array}{c}\text { P- } \\
\text { value }\end{array}$} \\
\hline & & No. $=20$ & No. $=20$ & & \\
\hline $\begin{array}{l}\text { Type of suture } \\
\text { repair for the defect }\end{array}$ & $\begin{array}{l}\text { Continuous } \\
\text { Interrupted }\end{array}$ & $\begin{array}{c}14(70.0 \%) \\
6(30.0 \%) \\
\end{array}$ & $\begin{array}{c}20(100.0 \%) \\
0(0.0 \%)\end{array}$ & $7.059 *$ & 0.008 \\
\hline $\begin{array}{l}\text { Type of suture material } \\
\text { used for the repair }\end{array}$ & \begin{tabular}{|l} 
PDS loop \\
Prolene
\end{tabular} & $\begin{array}{c}3(15.0 \%) \\
17(85.0 \%)\end{array}$ & $\begin{array}{l}15(75.0 \%) \\
5(25.0 \%) \\
\end{array}$ & $14.55^{*}$ & 0.001 \\
\hline $\begin{array}{l}\text { Operation time } \\
\text { in minutes }\end{array}$ & \begin{tabular}{|l} 
Mean \pm SD \\
Range
\end{tabular} & $\begin{array}{c}86.00 \pm 20.88 \\
50-120 \\
\end{array}$ & $\begin{array}{c}187.50 \pm 30.24 \\
150-250 \\
\end{array}$ & $-12.353 \cdot$ & 0.001 \\
\hline $\begin{array}{l}\text { Intra-operative } \\
\text { Bleeding in cc }\end{array}$ & $\begin{array}{l}\text { Mean } \pm \text { SD } \\
\text { Range }\end{array}$ & $\begin{array}{c}205.00 \pm 153.81 \\
50-600\end{array}$ & $\begin{array}{c}472.50 \pm 135.21 \\
300-750\end{array}$ & $-5.841 \bullet$ & 0.001 \\
\hline $\begin{array}{l}\text { Intra-operative Blood } \\
\text { Transfusion }\end{array}$ & $\begin{array}{l}0 \mathrm{CC} \\
500 \mathrm{CC}\end{array}$ & $\begin{array}{c}20(100.0 \%) \\
0(0.0 \%)\end{array}$ & $\begin{array}{l}17(85.0 \%) \\
3(15.0 \%)\end{array}$ & $3.584^{*}$ & 0.48 \\
\hline
\end{tabular}

*: Independent t-test

As regard the type of suture material used for repair of the defect, PDS loop was used in 3 patients $(15 \%)$ in group $\mathrm{A}$ in comparison to 15 patients $(75 \%)$ in group B. On the other hand, prolene was used in 17 patients $(85 \%)$ compared to 5 patients $(25 \%)$ in group B. This whowed a highly significant statsiistical difference between the studied groups ( $\mathrm{p}$ value 0.0 ).

Operative time was mush shorter in group A. In group $\mathrm{A}$, the mean operative time was 86 minutes (ranged from 50-120 minutes). In group B patients, the mean operative time was 187 minutes (ranged from 150 - 250 minutes). So, the type of the procedure had a major effect on the length of the operation and the risks implied and showed a highly significant statistical difference between the studied groups ( $\mathrm{p}$ value 0.0 ).

The most important and fearful intraoperative complication is intra-operative bleeding. The amount of bleeding ranged from $50 \mathrm{cc}$ to about 
$600 \mathrm{cc}$ in group A during hernioplasty with a mean of $205 \mathrm{cc}$ compared to 300 to $750 \mathrm{cc}$ in patients with group B with a mean of about $470 \mathrm{cc}$. In all cases bleeding stopped by the usual haemostatic measures. This bleeding was controllable and passes without any significant complications. This was with a highly significant statistical difference with P-value of 0.00 .

Accordingly, some patients needed blood transfusion intaoperatively. No one needed blood transfusion in patients of group A during hernioplasty compared to 3 patients in group B needed transfusion of about $500 \mathrm{cc}$ during abdominoplasty and hernioplasty. This showed no statistical difference at all between the studied groups "p value 0.48 " as shown in table (2).

Table (3) explained the data related to early post-operative follow-up. Fever developed in 5 patients $(25 \%)$ in group A, but it developed in 7 patients $(35 \%)$ in group B. Fever ranged from 37 to 38.5 degrees with a mean of 37.31 degrees in group $\mathrm{A}$, actually the same range for patients in group B. This carries no statistical difference between both

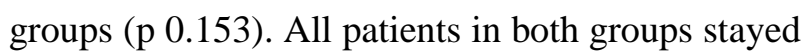
in hospital in a range of 1 to 3 days with no significant difference.

Table (3): The data related to early post-operative follow-up

\begin{tabular}{|c|c|c|c|c|c|}
\hline & Hernioplasty & Abdominoplasty & \multirow{2}{*}{$\begin{array}{c}\text { Test } \\
\text { value }\end{array}$} & \multirow{2}{*}{$\begin{array}{c}\text { P- } \\
\text { value }\end{array}$} \\
\hline & & No. $=20$ & No. $=20$ & & \\
\hline Post-Operative Fever & $\begin{array}{l}\text { No } \\
\text { Yes }\end{array}$ & $\begin{array}{c}15(75.0 \%) \\
5(25.0 \%)\end{array}$ & $\begin{array}{l}13(65.0 \%) \\
7(35.0 \%)\end{array}$ & $3.750 *$ & 0.153 \\
\hline Degree of fever & $\begin{array}{l}\text { Mean } \pm \text { SD } \\
\text { Range }\end{array}$ & $\begin{array}{c}37.31 \pm 0.57 \\
37-38.5\end{array}$ & $\begin{array}{c}37.31 \pm 0.55 \\
37-38.5\end{array}$ & $-1.463 \cdot$ & 0.152 \\
\hline Hospital Stay in days & $\begin{array}{l}\text { Mean } \pm \text { SD } \\
\text { Range }\end{array}$ & $\begin{array}{c}1.95 \pm 0.69 \\
1-3\end{array}$ & $\begin{array}{c}2.00 \pm 0.46 \\
1-3\end{array}$ & $-0.271 \bullet$ & 0.788 \\
\hline $\begin{array}{l}\text { Total drain output in } \mathrm{ml} \\
\text { (range) }\end{array}$ & $\begin{array}{l}\text { Mean } \pm \text { SD } \\
\text { Range }\end{array}$ & $\begin{array}{c}225.00 \pm \\
100.66 \\
100-400\end{array}$ & $\begin{array}{c}1655.00 \pm 345.61 \\
900-2100\end{array}$ & $-17.766 \bullet$ & 0.001 \\
\hline Drain duration in days & $\begin{array}{l}\text { Mean } \pm \text { SD } \\
\text { Range }\end{array}$ & $\begin{array}{c}5.50 \pm 1.61 \\
3-8\end{array}$ & $\begin{array}{c}11.45 \pm 2.09 \\
9-15\end{array}$ & $-10.097 \cdot$ & 0.001 \\
\hline $\begin{array}{l}\text { Mobility in days after } \\
\text { surgery }\end{array}$ & $\begin{array}{l}\text { First } \\
\text { Second } \\
\text { Third }\end{array}$ & $\begin{array}{c}16(80.0 \%) \\
4(20.0 \%) \\
0(0.0 \%)\end{array}$ & $\begin{array}{c}2(10.0 \%) \\
16(80.0 \%) \\
2(10.0 \%)\end{array}$ & 20.089 & 0.001 \\
\hline dy satisfaction & $\begin{array}{l}\text { No } \\
\text { Yes }\end{array}$ & $\begin{array}{c}11(55.0 \%) \\
9(45.0 \%)\end{array}$ & $\begin{array}{c}0(0.0 \%) \\
20(100.0 \%)\end{array}$ & 15.172 & 0.001 \\
\hline
\end{tabular}

We used a negative suction drainage system in order to drain any possible collection above the mesh placed after repair of the hernia defect and removed when the discharged serous fluid was less than $50 \mathrm{cc}$ daily. In patients of group A, the drain was removed after a range of 3 to 8 days with a mean of 5.5 days in comparioson to a range of 9 to 15 days with a mean of 11.45 days in group B. This showed a highly significant statistical difference with a $\mathrm{p}$ value of 0.0 .
The drain output was recorded daily and the total output is calculated. It ranged from $100-$ $400 \mathrm{cc}$ with a mean of $225 \mathrm{cc}$ in group A in comparison to a range of $900-2100 \mathrm{cc}$ with a mean of $1655 \mathrm{cc}$ in group B. This carried a highly significant statistical difference.

We encouraged patients to move as soon as possible. In group A, 16 patients $(80 \%)$ moved from bed in the 1st day, 4 patients in the 2nd day $(20 \%)$ and no one in the 3rd day. On the other side in group B, 2 patients $(10 \%)$ moved from bed in the 1 st day, 16 patients $(80 \%)$ in the 2 nd day and 2 patients $(10 \%)$ in the 3 rd day. This carried a highly significant difference between the studied groups.

As regards patient satisfaction from the point of aestheticism, only 9 patients in group A $(45 \%)$ had reached their wanted point of satisfaction in comparison to all 20 patients in group B have reached the point of body aestheticism and satisfaction wih a highly significant statistical difference in favour of combined abdominoplasty and hernioplasty.

\section{Postoperative complications:}

Table (4) showed the early postoperative complications which were detected during the patient's hospital stay and after discharge from hospital within 30 days from operation date and the late post-operative copmlications within a year after surgery.

Table (4): The early postoperative complications.

\begin{tabular}{|c|c|c|c|c|c|}
\hline & Hernioplasty & Abdominoplasty & \multirow{2}{*}{$\begin{array}{c}\text { Test } \\
\text { value* }\end{array}$} & \multirow{2}{*}{$\begin{array}{c}\text { P- } \\
\text { value }\end{array}$} \\
\hline & & No. $=20$ & No. $=20$ & & \\
\hline \multirow{7}{*}{$\begin{array}{l}\text { Early postoperative } \\
\text { comlications }\end{array}$} & No & $11(55.0 \%)$ & $7(35.0 \%)$ & \multirow{7}{*}{14.000} & \multirow{7}{*}{0.030} \\
\hline & Haematoma & $0(0.0 \%)$ & $2(10.0 \%)$ & & \\
\hline & Minor wound dehiscence & $3(15.0 \%)$ & $0(0.0 \%)$ & & \\
\hline & Necrosis of the umbilicus & $0(0.0 \%)$ & $2(10.0 \%)$ & & \\
\hline & Seroma & $4(20.0 \%)$ & $5(25.0 \%)$ & & \\
\hline & Wheezy Chest & $2(10.0 \%)$ & $0(0.0 \%)$ & & \\
\hline & Wound infection & $0(0.0 \%)$ & $4(20.0 \%)$ & & \\
\hline \multirow{3}{*}{$\begin{array}{l}\text { Late post operative } \\
\text { complications }\end{array}$} & No & $15(75.0 \%)$ & $12(60.0 \%)$ & \multirow{3}{*}{13.429} & \multirow{3}{*}{0.014} \\
\hline & Hypertrophic scar & $2(10.0 \%)$ & $6(30.0 \%)$ & & \\
\hline & $\begin{array}{l}\text { Prolonged pain } \\
\text { after } 6 \text { months }\end{array}$ & $3(15 \%)$ & $2(10.0 \%)$ & & \\
\hline \multirow{4}{*}{$\begin{array}{l}\text { Hernia development } \\
\text { within } 2 \text { years after } \\
\text { surgery }\end{array}$} & No & $11(55.0 \%)$ & $20(100.0 \%)$ & \multirow{4}{*}{11.613} & \multirow{4}{*}{0.009} \\
\hline & Left oblique inguinal & $2(10.0 \%)$ & $0(0.0 \%)$ & & \\
\hline & $\begin{array}{l}\text { Rerma } \\
\text { Recurrent incisional }\end{array}$ & $5(25.0 \%)$ & $0(0.0 \%)$ & & \\
\hline & $\begin{array}{l}\text { Right oblique inguinal } \\
\text { hernia }\end{array}$ & & $0(0.0 \%)$ & & \\
\hline
\end{tabular}

*: Independent t-test

The early complications that have occurred in both groups. Haematoma was detected in 2 patients $(10 \%)$ in group B while it did not happen at all in any patient in group A. Also, minor wound dehiscence has occurred in 3 paients $(15 \%)$ in group B and in no one in group A. This wound dehiscence (minor necrosis) involved usually the 
center of the flap, which was allowed to heal secondary and managed conservatively by daily dressings with wound building agents without the need for secondry sutures.

Necrosis in the umbilicus has occurred in 2 patients $(10 \%)$ in group B while, did not occur in any patient in group A. The umbilicus didn't lose its vascularity or its shape and it was managed conservativel by daily dressings.

Seroma was defined as a fluid collection detected by palpation on clinical examination when patients attend for routine follow-up clinic appointments. Seroma was revealed in 4 patients in group A $(20 \%)$ while in group B, 5 patients $(25 \%)$ developed seroma. It was managed conservatively in the form of strong antibiotics and ultrasound guided aspiration was done in 3 of these patients from group B.

Chest infection happened only in 2 patients $(10 \%)$ in group A and no one in group B and it was managed conservatively using strong antibiotics and bronchodilators.

Wound infection was defined as redness, discharge of pus from the wound. Wound infection has occurred in 4 patients in group B (20\%) and in no one in group A. From all these data, there was a statistical difference between the two groups $(p$ value 0.03 ).

As regards other late post-opertive complications, hypertrophic scar happened in 2 patients only $(10 \%)$ in group A compared to 6 patients $(30 \%)$ in group B. Steroid injections were used in 3 of there patients to manage these scars with satisfactory results. In group A, 3 patients (15 $\%$ ) complained of prolonged pain after 6 months of surgery in comparison to 2 patients $(10 \%)$ in group B. This pain was totally controllable by nonsteroidal anti-inflammatory agents. This showed a significant difference ( $p$ value 0.014 ).

\section{Recurrence of hernia:}

To detect recurrence of hernia after surgery, we standed on a combination between clinical examination and radiological modalities in the form of ultrasound (US) for abdomen and pelvis in case of suspected recurrence.

In group A patients, oblique inguinal hernia developed in 2 patients $(10 \%)$ on the lesft side and also in 2 patients on the right side (10\%) compared to no one in group B. The most important recurrence is recurrent incisional hernia which occurred in 5 patients $(25 \%)$ in group A. From the data mentioned above, there was a strong statistical difference of interest between the studied groups "p 0.009" with a strong indication that abdominoplasty is urgently needed in addition to hernioplasty to repair the deficient anterior abdominal wall and to decrease the incidence of recurrence.

\section{DISCUSSION}

Abdominoplasty theoretically allows covering of the repaired hernia defect with previously unmanipulated anatomical planes of the anterior abdominal wall providing a decreased risk of infection. This construction of the flap allows for a full assessment of the anterior abdominal wall before making the decision of the technique to be performed. Nevertheless, surgeons have been reluctant in the past years to combine these 2 methods (abdominoplasty in addition to hernioplasty) in a single act claiming an increasing operative time, a possible compromise on the vascularity of the abdominal skin and fat, and delayed healing, all of which may worsen outcomes ${ }^{(\mathbf{1})}$.

However, not everyone shared this hypothesis. Hughes et al. ${ }^{(7)}$ demonstrated that an abdominoplasty at the time of hernia repair reduces the incidence of wound complications and the possibility of hernia recurrence, and recently, Reid and Dumanian ${ }^{(8)}$ demonstrated a reduction in the incidence of wound infection.

In our study, morbidity was not increased and only the operative time was found to be longer though without statistical significance when performing the combined abdominoplasty and hernioplasty.

In addition, many plastic surgeons rather avoid the placement of meshes to reinforce the anterior abdominal wall for fear of infection, dehiscence, and extrusion or associated chronic pain risk with the potential need for removal of the mesh later on ${ }^{(\mathbf{1})}$.

Cooper et al. (9) demonstrated that an abdominoplasty in the setting of a incisional hernia repair can improve patients satisfaction, particularly appearance, hygiene, and self-confidence.

Saariniemi et al. (10) published a
prospective study that concluded that
abdominoplasty significantly improved quality of
life, body satisfaction, effectiveness, sexual
functioning, selfesteem, and mental health for
patients with inciosnal hernias.


In our study, we achieved similar results in patients with moderate-sized incisional hernias. The combination of abdominoplasty with hernioplasty at the same time in our study had a positive impact on the quality of life of these patients when compared to the isolated hernioplasty as verified by follow-up (comments about reduced back pain, local hygiene, easier dressing and walking, improvement of incontinence and constipation, etc).

Patients' satisfaction, quality of life improvement, and low morbidity allow us to strongly recommend a simultaneous hernioplasty and abdominoplasty for wellselected patients with incisional hernias.

However abdominoplasty, in itself, a complex operation that requires adequate training and experience and it should be performed by specialized surgeons.

Umbilical vascular preservation is of the utmost importance with abdominoplasty procedures. Simultaneous abdominoplasty with incisional hernia repair has been demonstrated to place the umbilicus at risk, with possibility of impairment or loss of its blood supply. Large incisional hernias can distort normal anterior abdominal wall anatomy and result in thinning of the overlying skin and soft tissue. Careful planning is a must intraoperatively to determine the safe point of entry and plane of dissection of the hernia to avoid umbilical ischemia. This planning takes into consideration the size of the hernia and its location relevant to the umbilical stalk. Also, fascial incisions away from the umbilical stalk is effective to preserve the perforating vessels ${ }^{(\mathbf{1 1})}$.

The addition of mesh reinforcement of the anterior abdominal wall at the time of abdominoplasty has been advocated. The exposure during an abdominoplasty allows for the placement of a large synthetic mesh by onlay technique, which is secured to bilateral anterior superior iliac spines under tension along the inguinal ligaments and to the lateral muscle wall of the lower abdomen.

The post-bariatric surgery patients' requently presents with an insional hernia and need for abdominoplasty following significant weight loss. The technique involved concomitant excision of excess adipocutaneous tissues and mesh repair of incisional hernia once the patient reaches his or her maximum weight loss at 12 to 18 months following the bariatric procedure. Typically, the incisional hernia repair involved an onlay of synthetic mesh after reinforcement or plication of the midline, the excess skin and soft tissue is then removed ${ }^{(11)}$.
An onlay mesh repair would not feasible in this case because a hole have to be created in the centre of the mesh to accommodate the umbilical stalk. This approach might result in a potential weak spot for a recurrence ${ }^{(11)}$.

From the parameters evaluated for differences between the 2 groups, the mean duration of the surgical procedure differed significantly in favor of the group B with combined abdominoplasty and hernioplasty procedure (76 minutes vs 187 minutes; $\mathrm{P}$ value 0.00 ). There was no significant intraoperative morbidity nor blood requirement.

The postoperative hospital stay (1.95 vs 2 days; P 0.788). No statistically significant difference in postoperative in-hospital stay between both groups.

There were no incidences of ischemia or skin necrosis during the first 30 days of follow-up. Four patients had a seroma in group A compared to 5 patients in group B with no statistical difference.

Necrosis in the umbilicus has occurred in 3 patients $(15 \%)$ in group A while did not occur in any patient in group A. The umbilicus didn't lose its vascularity or its shape and it was managed conservativly by daily dressings.

Skin-flap necrosis was minimal in our study, occurring in 3 patients in group A compared to 2 ptients in group B.

With a mean of 2 years of follow-up, there were no recurrences in patients of the group B who underwent combined abdominoplasty with hernioplasty. In patients of the group A, 5 recurrences were detected and 4 patients developed oblique inguinal hernias with a highly significant statistical difference in favor of abdominoplasty. Two patients developed abdominal wall pain that resolved within 8 months of surgery.

This study showed that performing a simultaneous abdominoplasty does not add morbidity to incisional hernia repair and allows improvement in quality of life, both in short term and long term.

In conclusion, abdominoplasty can be performed in combination with hernia repair in patients with incisional hernias, especially when associated with large sized defects or divarication of recti. Simultaneous techniques can be safely performed with the same morbidity and recurrences, but with major quality of life improvement and superiority over hernioplasty alone. 


\section{REFERENCES}

1. Moreno-Egea A, Campillo-Soto Á, Morales-Cuenca G (2016). Does abdominoplasty add morbidity to incisional hernia repair? A randomized controlled trial. Surgical innovation, 23(5): 474-480.

2. Skipworth J, Khan $\mathbf{Y}$, Motson $\mathbf{R}$, Arulampalam T, Engledow A (2010): Incisional hernia rates following laparoscopic colorectal resection. International Journal of Surgery, 8(6): 470-473.

3. Koolen P, Ibrahim A, Kim K, Sinno H, Lee B, Schneider B, Lin S (2014): Patient selection optimization following combined abdominal procedures: analysis of 4925 patients undergoing panniculectomy/ abdominoplasty with or without concurrent hernia repair.Plastic and reconstructive surgery, 134(4): 539e-550e.

4. Ielpo B, Cabeza J, Jimenez D, Delgado I, Torres A (2011): Abdominal pseudocyst complicating incisional hernia repair: our experience and literature review. Hernia, 15(2): 233-237.

5. Robertson J, Jorge I, Gardner P, Grant J, Fix R, Vásconez L (2003): Abdominoplasty repair for abdominal wall hernias. Annals of plastic surgery, 51(1): 10-16.

6. Bruner TW, Salazar-Reyes H, Friedman JD (2009): Umbilical hernia repair in conjunction with abdominoplasty: a surgical technique to maintain umbilical blood supply. Aesthetic surgery journal, 29(4): 333-334.
7. Hughes KC, Weider $\mathrm{L}$, Fischer $\mathrm{J}$ et al. (1996): Ventral hernia repair with simultaneous panniculectomy. Am Surg., 62: 678-681.

8. Reid RR, Dumanian GA (2005): Panniculectomy and the separation-of-parts hernia repair: a solution for the large infraumbilical hernia in the obese patient. Plast Reconstr Surg., 116:1006-1012.

9. Cooper JM, Paige KT, Beshlian KM, Downey DL, Thirlby RC (2008): Abdominal panniculectomies: high patient satisfaction despite significant complication rates. Ann Plast Surg., 61:188-196.

10. Saariniemi K, Salmi A, Peltoniemi H, Helle M, Charpentier P, Kuokkanen H (2014): Abdominoplasty improves quality of life, psychological distress, and eating disorder symptoms: a prospective study. Plastic surgery international, 2014: 197232.

11. McKnight CL, Fowler JL, Cobb WS, Smith DE, Carbonell AM (2012): Concomitant sublay mesh repair of umbilical hernia and abdominoplasty. Can J Plast Surg., 20(4): 258- 260 . 